\title{
NATIONAL SERVICE: RAMC 1959-1961
}

\author{
John Chippendale \\ Retired General Practitioner, Lancaster
}

\section{INTRODUCTION}

Present-day medical students have many problems, one of which must be being saddled with a large debt on qualification. Also, if aiming to be general practitioners, they must train for three years after pre-registration, with one of these years working with a general practitioner trainer as a registrar. It is therefore nine years before they can be a partner in a general practice. There were different problems when I decided on a career in medicine in 1951. In 1947 the National Service Act was passed by a majority in Parliament of only ten votes and thereafter all 18-year-old males had to do two years in the services and five years in the reserves. It was realised by the administrators that it would be a good idea to swell the ranks of the regular Royal Army Medical Corps (RAMC) with qualified doctors. The services waited the five or so years to get a doctor/officer rather than a raw recruit.

\section{DEFERMENT FOR SEVEN YEARS}

In the summer of 1951, a few months before my 18th birthday, I received papers informing me that I would be called up for National Service unless I was in professional training, which allowed deferment. I had been offered a place at Leeds University Medical School and whether I went into the Army at 18 as a private or at 24 as an officer depended on my A level results. As it happened my results were all right and I took up my university place in October 1951. I was deferred and this deferment was to go on for over seven years. When doing professional examinations one was allowed one failure but a second failure meant one was in the army - a good way to concentrate the mind. On qualification in 1957 the one year of pre-registration was allowed and in 1958 I was also allowed to be an obstetrics House Officer and take the D Obst RCOG examination. There was talk of National Service ending but it did not end soon enough for me and on the 27th of April 1959 I was on a train to Crookham Barracks, Aldershot, to commence my basic training to become a first lieutenant in the RAMC. I left behind my wife and our first child, born in the February of the year.

\section{BASIC TRAINING}

The basic training took six weeks, with the first fortnight taken up with learning how to be an army officer. Before getting a uniform one was drilled in civilian clothes, trousers tucked in socks. If one thought one had had status as a Senior House Officer in hospital it was quickly lost as a young Guards NCO drilled one. It did not help at all when he called us "gentlemen". There were 17 of us and we were at the bottom of the heap again. However at the age of 25 one adapts and accepts and a camaraderie developed amongst us. We even looked quite cheerful when photographed after we had been issued with our uniforms, hats and officers' canes.

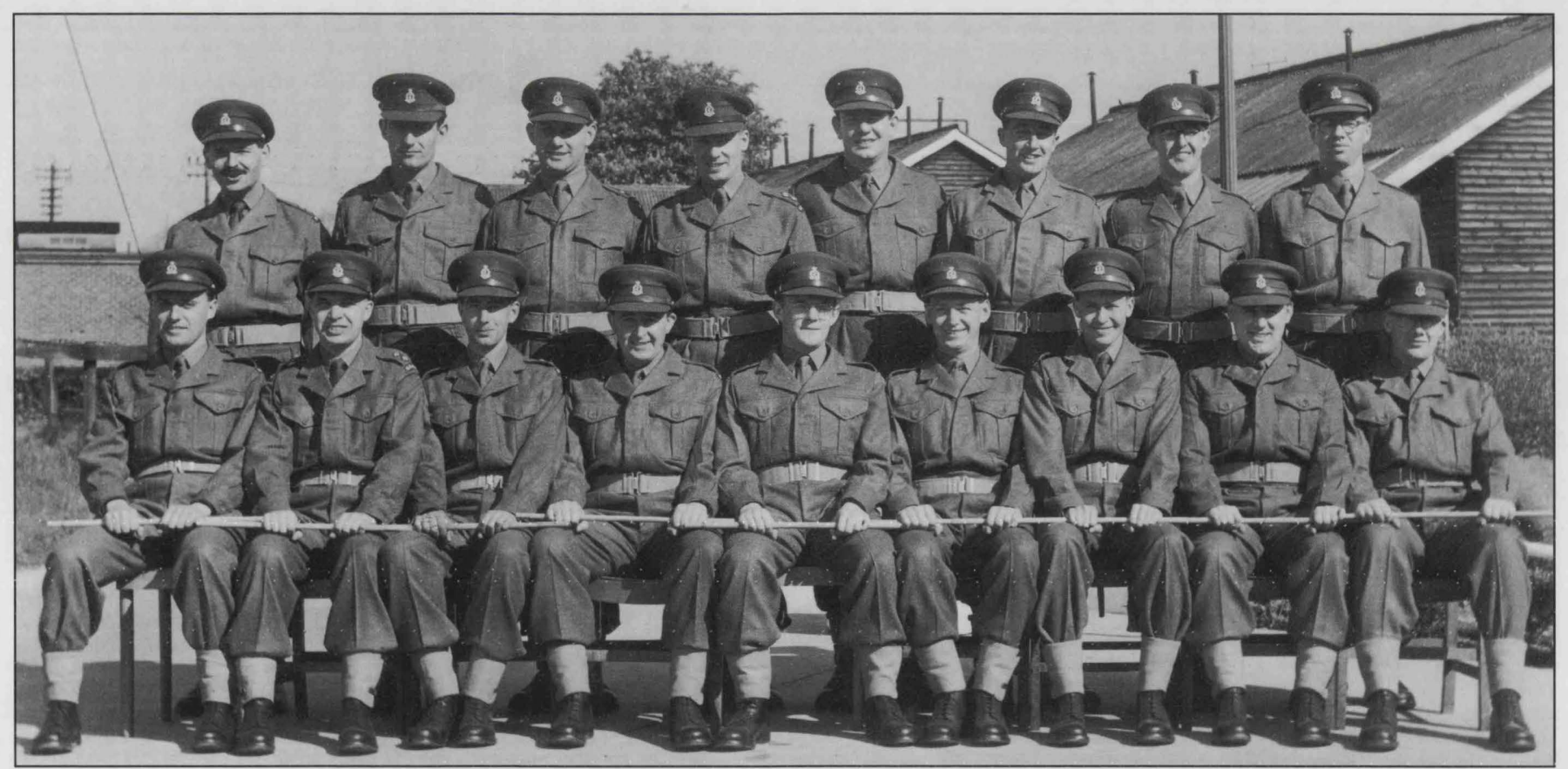

"We even looked quite cheerful" (photo author's personal possession). 
The second fortnight of training took us to the RAMC College at Millbank in London. Here we were allowed to wear civilian clothes and rubbed shoulders with senior career RAMC officers - true gentlemen of the era. One did not walk out through the front door of the college unless wearing a hat; fortunately there was a side entrance one could slip through. It was nice to have the Tate Gallery next door to the college. The purpose of this fortnight at the college was to give an introduction to tropical medicine, a discipline where the RAMC led the world and one could say the time was not wasted. A few of our group were posted to the tropics. The last fortnight was spent at Keogh Barracks, Mytchett, near Aldershot. Here the emphasis was on training for battle situations, knowing about slit trench latrines and firing a revolver, which an RAMC officer may carry for self-defence. Mytchett was enlivened by the commanding officer, Colonel Niven, who was actor David Niven's brother. Needless to say there was role-play as it is called nowadays.

\section{POSTING}

One could state one's preferences before the postings were announced. With our baby we did not fancy the Far East but did try for a posting to Germany, to the British Army of the Rhine. On the fateful day, when one of our group, who said he liked birdwatching, was posted to St Kilda, I was posted to become the garrison medical officer at Bulford Camp on Salisbury Plain. It was not as bad as I first thought, as I soon found I had a colleague who was medical officer to the families and who has remained a friend to this day. We worked together as a two man general practice. We found we had two other colleagues at Tidworth and Larkhill who were interested in starting a roster for overnight duty and worked one in four on. My work had been hospital-based so far and I look back on my army days and think that I was basically a trainee (registrar) in general practice without a trainer.

\section{LOOKING AFTER THE TROOPS}

I think that I was probably responsible for over 1000 troops. I was based in a reasonably well-appointed hutted medical centre and had several orderlies to help me. They were Other Ranks in the RAMC and also doing their National Service. They had done basic training for their work and were somewhat interested in medicine but were more interested in the workings of cars. I could not understand why the Gee's linctus bottle emptied so rapidly until I discovered that my orderlies were using it to dilute alcohol to taste - a sort of Bulford Kir. One could not say the days were too full and my colleague and I played squash every lunchtime! One was busier when covering for both troops and families when either of us was on leave. When on duty for the three camps one could be quite busy and one was also learning the work of general practice. Duty nights posed some problems for me because the only home I could find for my wife and our baby was 10 miles away from Bulford on the Hampshire-Wiltshire border. It was an idyllic thatched cottage. After a few unhappy attempts to be 'on-call' from home I decided to stay in the officers' mess when on duty at night. A National Service officer was not allowed an army quarter but through getting to know the Quartermaster at Netheravon Camp, close to Bulford, I was offered a quarter if I would start my day by doing the Netheravon sick parade. Previously Netheravon 'sick' had been trucked down to Bulford. Therefore, after nine months we left our nice little cottage to live in an officer's quarter - unheard of for a National Serviceman and we had a share of a batman (woman).

\section{PROMOTION}

After one year, a National Service doctor automatically became a captain. I was just getting used to wearing three pips at the shoulder when something happened which I think was unique in the annals of RAMC National Service. There was a dearth of career RAMC officers and the colonel Assistant Director of Medical Services (ADMS), Salisbury Plain District, needed a deputy (DADMS) and there was no career person available. He offered my colleague the post as he was senior to me and, when he declined, the job was offered to me! I accepted and became a temporary major. I got an extra eight shillings (40p) a day, bringing my salary up to $£ 967.25$ a year and I think this salary increase swayed me. A National Service officer in a quarter and now a major sporting crowns at the shoulder was indeed unique. Many regular officers, still captains after many years, thought I had signed up to be a regular. Now my day started with the sick parade but then I went up to headquarters on the camp and did 'administration' or drove off with the colonel to inspect other RAMC facilities on Salisbury Plain in a Humber staff car. My Colonel was an engaging character and great raconteur, especially when he got onto the subject of 'the fog of war'. He had been a young regimental medical officer with the British Expeditionary Force in France in 1940 prior to Dunkirk. He had graphic descriptions of how the rapid advance of the Germans created chaos for the British and French troops - "German troops wherever you looked".

\section{MORE ABOUT THE WORK}

Part of the 3rd Division, the rapid reaction force of the day, was based at Bulford in 1959. These troops could be flown off to any part of the world at short notice. Their inoculations were my concern and I have memories of queues of soldiers getting inoculations on Friday afternoons - to give them the weekend to get over any reactions! After several faints and many white faces I used screens so that the next man did not watch the injection being given. Needles were sterilised using boiling oil. The 3rd Division also had to have talks on prevention of the venereal diseases. Addressing several hundred troops on this subject was a garrison medical officer's nightmare. Lectures were given on first aid and this started off an interest for me and I used a Bulford case when giving lectures in my other life. This was an example of how not to treat a bleeding arm. A soldier using a cold chisel in the vehicle pool sustained damage to a large vein at the elbow with much bleeding. It was not far to the medical centre so he was marched there by an NCO with arm swinging and dripping blood. My orderlies elevated the arm and applied local pressure - end of bleeding - end of problem.

\section{SOME MEMORABLE CASES}

Chicken pox in an adult This was an officer in his forties who admitted to a rather protected childhood. His young children caught chicken pox (varicella) and he was susceptible and developed the disease with a severe rash. He was generally ill and I became most concerned. Discussion with my colleague did not help as he asked "are you sure it isn't smallpox?" Out came the books and we read that there is no rash on the palms in chicken pox. I revisited on the pretext of "just passing" and contrived to check that there was no rash on the palms. Recovery occurred. 
A first cot death One day I was called to a caravan where a young soldier and his wife had found their baby white and lifeless in its cot. In my career I think I attended three or four similar cases but the anguish of those parents, the first I attended, remains with me.

Savaged by a horse One of the regiments at Tidworth was the Royal Horse Artillery. This was a regiment with career officers who were often horse owners. One day one of the officers hobbled into my surgery saying he had been savaged in the groin by a stallion. On the couch he gingerly opened a pad of cotton wool to reveal testes devoid of the scrotum, which had been lacerated and opened by the horse's bite. It was a simple procedure at Tidworth Military Hospital for the wound to be closed over a drain.

More horse trouble One evening when I was on call there was a general alarm, as a very senior officer had not returned from an evening ride on the plain. Many searches were made over his probable route but he was not found. Then in semi-darkness a search party heard faint cries and found the officer trapped under his horse, which had died under him and rolled onto his leg. He was released and insisted on going to his quarter rather than to hospital. I was called to check him over and look at the leg. At the house he greeted me with large whisky in his hand and insisted I had one too because of the anxiety I must have suffered. The leg was very badly bruised but as he was so well in himself I recommended no active treatment. It was only later that I thought about the general effects of crush injury and had even more anxiety!

\section{CONCLUSION}

Eventually my two years came to an end. If a three-year commission had been taken an RAMC officer could collect a bounty of $£ 600$ at the end of the active part of their service. When my service started the shortest commission was four years and I did not wish to be in the army for so long. So all I had was a rather remarkable career as a National Serviceman and nice memories of being in the south and especially of living in the thatched cottage and exploring Salisbury Plain and the surrounding countryside. Later on when I applied to join Drs J Hood and GH Anderson, who had both been RAF officers, and Dr RJ Howat, Lt. Colonel RAMC, at Dalton Square, Lancaster, my service record may have been useful to me. 1961.

By the way conscription for National Service ended in

\section{POSTSCRIPT}

Shortly after I had started drafting this article I read that 'those who did national service spent two years moaning about it and then a lifetime talking about it'.

\section{Acknowledgement}

I was stimulated to write about my national service by reading The Conscript Doctors, Memories of National Service, compiled and edited by Dr John SG Blair and published by The Pentland Press. The figures of the parliamentary majority are from this book as are several of the dates about the duration of National Service. I recommend the book as a good read for ex-national service men and students of the history of the period 1947 to 1963. 